\title{
PERAN LOCUS OF CONTROL TERHADAP KINERJA KARYAWAN MELALUI KEPUASAN KERJA PADA KARYAWAN PT. ILHAM HASIL MANDIRI KABUPATEN SIDOARJO
}

\author{
Prayoga Putra Wardhana \\ Universitas Negeri Surabaya \\ prayogawardhana16080574137@mhs.unesa.ac.id
}

Abstract

\begin{abstract}
The study aims to determine and analyze the effect of Locus of control on employee performance through job satisfaction. Research object at PT. Ilham Hasil Mandiri Sidoarjo City, with a sample of 44 of 51 employees, this research is used as a Structural Equation Model (SEM) with the assistance of Smart Pls 3.0 software as the statistical analysis. The results of this study indicate that the Locus of control has a positive and significant effect on employee performance, the Locus of control has a significant negative effect on job satisfaction, job satisfaction has a positive and significant effect on employee performance, the Locus of control has a positive and significant effect on employee performance through job satisfaction.
\end{abstract}

Keywords: employee performance; job satisfactions; locus of control.

\section{PENDAHULUAN}

Kekayaan akan sumber daya alam yang ada di Indonesia sangatlah melimpah maka harus dimanfaatkan semaksimal mungkin untuk kesejahteraan penduduk, dan didalamnya adalah sumber daya genetik ayam lokal yang dimiliki oleh Indonesia. Banyak dilaporkan oleh para ilmuwan bahwasannya Indonesia merupakan salah satu pusat keanekaragaman genetik ayam lokal di dunia (Hidayat, 2012). Untuk itu jagung merupakan komoditi strategis serta mempunyai peluang untuk dikembangkan karena jagung merupakan bahan baku dasar untuk pembuatan pakan ternak (Alamsyah, 2019). Banyaknya perusahaan industri pakan ternak di Indonesia khususnya Jawa Timur maka memacu satu sama lain dari setiap pesaing agar selalu meningkatkan kualitas hasil produk dan mencapai penjualan yang tertinggi (Maulidya, et al., 2019).

Perusahaan harus mampu mengelolah aset dari sumber daya manusia yang dimilikinya secara optimal. Karena pentingnya peranan dari sumber daya manusia, maka perusahaan dituntut untuk memiliki karyawan atau sumber daya manusia yang unggul dan berkualitas yang dapat memberikan kontribusi penuh untuk kesuksesan perusahaan. Karena sumber daya manusia adalah kunci penggerak dalam suatu perusahaan, sukses atau tidaknya perusahaan tergantung oleh sumber daya manusia yang dimiliki. Maka diperlukan pengelolaan sumber daya manusia secara optimal dan dilakukan dengan baik dan benar (Agustyna, 2020). Sumber daya manusia merupakan faktor yang menentukan keunggulan dan kemajuan perusahaan. Bahwa sumber daya manusia adalah unsur terpenting dari unsur yang lain, seperti bahan baku dan mesin (Arda, 2017).

Menurut Dudi, et al. (2019), Sari (2018), Subhan, et al. (2019), dan Yusnaena \& Hayati (2018), locus of control berpengaruh positif dan signifikan terhadap kinerja karyawan. Menurut Indriasari \& Angreany (2019), locus of control tidak berpengaruh positif dan siginifikan terhadap kinerja karyawan. Menurut Changgriawan (2017), Mokoagow, et al. (2020), dan Indrawati (2013), kepuasan kerja berpengaruh positif dan signifikan terhadap kinerja karyawan. Menurut Arda (2017), kepuasan kerja tidak berpengaruh positif dan signifikan pada kinerja karyawan. Menurut Narendra (2018), Lisnawati, et al. (2019), dan Chhabra \& Mohanty (2016), locus of control berpengaruh positif dan signifikan terhadap kepuasan kerja. Menurut Candra (2019), dan Mulyadi, et al. (2018), locus of control tidak berpengaruh positif dan signifikan terhadap kepuasan kerja.

Penelitian ini dilakukan di PT. Ilham Hasil Mandiri Kabupaten Sidoarjo, yang di mana perusahaan yang bergerak pada industri pertanian pakan ternak. perusahaan ini sebagai pemasok jagung atau 
bahan baku dasar pakan ternak. PT. Ilham Hasil Mandiri merupakan perusahaan yang dapat dibilang cukup besar karena terletak pada tiga Kota yaitu Sidoarjo, Lamongan dan Mojokerto. Untuk jumlah karyawannya cukup banyak yang bisa dibilang bervariasi dan heterogen untuk hal berpikir dan juga berperilaku. Karena banyaknya karyawan dan juga terdapat sebuah permasalahan atau fenomena maka dijadikanlah sebuah penelitian yang bertujuan untuk menguji kebenaran dari fenemona tersebut.

Terdapat permasalahan (fenomena) yang ada di PT. Ilham Hasil Mandiri. bahwa beberapa karyawan yang mempunyai kemauan dan semangat yang tinggi untuk meningkatkan kemampuan dan juga ada yang cenderung pasrah tidak inisiatif ketika bekerja, tidak suka berusaha dan kurangnya tanggung jawab karyawan terhadap pekerjaannya. Dalam bekerja setiap karyawan mempunyai target dan tujuan, tujuan ini bersifat kelompok maupun individu. Tujuan karyawan dalam bekerja yaitu untuk mencari uang untuk memenuhi kebutuhan hidup akan tetapi amat disayangkan kurang memerhatikan indikator dari kinerja karyawan. Karena perusahaan mengukur kinerja karyawanya dengan acuan seberapa jauh karyawan tersebut mampu bekerja.

Penelitian ini bertujuan untuk memperoleh pengetahuan baru dan untuk menguji suatu teori yang sudah ada. Sehingga didapatkan hasil penelitian yang dapat memperkuat atau menggugurkan pengetahuan atau teori yang sudah ada.

\section{KAJIAN PUSTAKA}

\section{Locus of Control}

Locus of control merupakan keberhasilan seseorang dalam mengendalikan diri yang berasal dari internal ataupun eksternal. Locus of control merupakan kondisi psikologis yang mengacu pada keyakinan individu bahwasannya cara dia berperilaku atas kendali mereka sendiri ataupun kendali yang berasal dari luar diri mereka (Narendra, 2018). Menurut Sari (2018), locus of control bagaimana cara pandang seseorang bahwa perilaku pada dirinya sebagai bentuk berhubungan pada orang lain atapun lingkungannya, dan juga sebagai keyakinan pada sumber yang menentukan perilakunya. Menurut Indriasari \& Angreany (2019), locus of control adalah sebagai cerminan dari kecenderungan seseorang untuk percaya bahwasannya diri sendiri yang dapat mengendalikan peristiwa dalam hidupnya atapun kendali dari luar.

\section{Kinerja Karyawan}

Kinerja karyawan merupakan hasil kerja baik secara kuantitas maupun kualitas yang telah dicapai dan dalam melakukan pekerjannya sesuai dengan tanggung jawab yang telah diberikan. Karyawan yang bekerja dengan baik adalah jika karyawan tersebut mempunyai kinerja yang unggul dan sehingga dapat menghasilkan kerja yang baik. karena faktor penentu dari keberhasilan perusahaan adalah dari seberapa baik kinerja karyawan yang dimilikinya. Maka perusahaan harus lebih memperhatikan kinerja karyawannya (Changgriawan, 2017). Menurut Arda (2017), kinerja adalah sebuah pencapaian hasil kerja yang di lakukan oleh karyawan selama periode tertentu dan dibandingkan dengan standar yang telah ditentukan oleh perusahaan. Menurut Agustyna \& Prasetyo (2020), kinerja karyawan dapat dilihat dari hasil yang telah dicapai sesuai dengan ukuran yang telah ditetapkan.

\section{Kepuasan Kerja}

Kepuasan kerja adalah di mana sikap emosional yang dirasakan oleh karyawan, kepuasan kerja harus diciptakan dengan sebaik-baiknya agar karyawan memiliki rasa kecintaan atas pekerjaanya, sehingga moral kerja dan kedisiplinan karyawan terus meningkat. Sikap ini dapat dicerminkan oleh moral kerja, kedisiplinan dan prestasi kerja (Mokoagow, 2020). Menurut Agustyna \& Prasetyo (2020), kepuasan kerja adalah sikap positif ataupun negatif dan juga puas atau tidaknya karyawan terhadap pekerjaannya. Menurut Arda (2017), kepuasan kerja merupakan sikap emosional individu karyawan yang mencintai pekerjaannya.

\section{Hubungan antar Variabel}

Menurut Dudi, et al. (2019), locus of control berpengaruh positif dan signifikan terhadap kinerja karyawan. Menurut Hayati \& Dewi (2016), locus of control berpengaruh positif dan signifikan 
Prayoga Putra Wardhana. Peran Locus of Control terhadap Kinerja Karyawan melalui Kepuasan Kerja pada Karyawan PT. Ilham Hasil Mandiri Kabupaten Sidoarjo

terhadap kinerja karyawan. Menurut Sari (2018), locus of control berpengaruh pengaruh positif dan signifikan terhadap kinerja karyawan. Menurut Subhan, et al. (2019), locus of control berpengaruh positif dan signifikan terhadap kinerja karyawan. Menurut Yusnaena (2018), locus of control berpengaruh positif dan signifikan terhadap kinerja karyawan. Menurut Mootalu, et al. (2019), locus of control pengaruh yang positif dan signifikan terhadap kinerja karyawan. Dari pendapat para ahli di atas, locus of control berdampak baik bagi kinerja seorang karyawan. Karena, locus of control merupakan bagaimana cara pandang individu untuk menyikapi bahwasannya keberhasilan karena diri sendiri.

H1: Diduga variabel locus of control berpengaruh positif terhadap variabel kinerja karyawan PT. Ilham Hasil Mandiri Sidoarjo.

Menurut Narendra (2018), locus of control berpengaruh positif dan signifikan pada kepuasan kerja. Menurut Chhbra \& Mohanty (2016), locus of control berpengaruh positif dan signifikan pada kepuasan kerja. Menurut Candra (2019), locus of control berpengaruh positif dan signifikan terhadap kepuasan kerja. Menurut Lisnawati (2019), locus of control berpengaruh positif dan signifikan pada kepuasan kerja. Menurut Chhbra \& Mohanty (2016), locus of control berpengaruh positif dan signifikan terhadap kepuasan kerja. Menurut Isnanto, et al. (2020), locus of control berpengaruh positif dan signifikan terhadap kepuasan kerja. Dari pendapat para ahli di atas, locus of control mampu memberikan pengaruh positif dan signifikan terhadap kepuasan kerja. karena locus of control adalah sikap kepribadian yang dimiliki oleh setiap karyawan. Tingginya locus of control yang dimiliki oleh karyawan dapat meningkatkan kepuasan kerja dari karyawan tersebut.

H2: Diduga variabel locus of control berpengaruh positif terhadap variabel kepuasan kerja karyawan PT. Ilham Hasil Mandiri Sidoarjo.

Menurut Ali \& Farooqi (2014), kepuasan kerja berpengaruh positif dan signifikan terhadap kinerja karyawan. Menurut Chandraningtyas, et al. (2015), kepuasan kerja berpengaruh positif dan signifikan terhadap kinerja karyawan. Menurut Agustyna \& Prasetyo (2020), kepuasan kerja berpengaruh positif dan signifikan terhadap kinerja karyawan. Menurut Arda (2017), kepuasan kerja berpengaruh positif dan signifikan terhadap kinerja karyawan. Menurut Changgriawan (2017), kepuasan kerja berpengaruh positif dan signifikan terhadap kinerja karyawan. Menurut Indrawari (2013), kepuasan kerja berpengaruh positif dan signifikan terhadap kinerja karyawan. Dari pendapat para ahli di atas, kepuasan kerja dapat membuat kinerja karyawan meningkat. Karena karyawan jika merasakan kepuasan dalam bekerja mereka akan mencari cara bagaimana bisa membuat hasil pekerjaannya maksimal.

H3: Diduga kepuasan kerja memberikan pengaruh positif terhadap kinerja karyawan PT. Ilham Hasil Mandiri Sidoarjo.

Menurut Narendra (2018), locus of control berpengaruh positif dan signifikan terhadap kinerja karyawan melalui kepuasan kerja. Menurut Isnanti et al. (2020), locus of control berpengaruh positif dan signifikan terhadap kinerja karyawan melalui kepuasan kerja. Menurut Ahmad et al. (2018), locus of control berpengaruh positif dan tidak signifikan terhadap kinerja karyawan melalui kepuasan kerja. Menurut Wahyuni \& Rosmida (2017), locus of control berpengaruh positif dan signifikan terhadap kinerja karyawan melalui kepuasan kerja. Rohman (2019) membuktikan kepuasan kerja memediasi locus of control terhadap kinerja karyawan. Menurut Wahyuni et al. (2016), kepuasan kerja memediasi locus of control terhadap kinerja karyawan. Dari pendapat para ahli, locus of control dapat memediasi locus of control pada kinerja karyawan.

H4: Diduga kepuasan kerja memediasi locus of control terhadap kinerja karyawan PT. Ilham Hasil Mandiri Sidoarjo. 


\section{METODE PENELITIAN}

Penelitian ini menggunakan metode penelitian kuantitatif. Responden adalah karyawan PT. Ilham Hasil Mandiri Sidoarjo dengan jumlah populasi 51 karyawan. Data yang digunakan merupakan data primer yang didapat dengan observasi dan penyebaran angket dengan teknik sampling jenuh. Adapun langkah-langkah dari teknik analisis data pada penelitian uji validitas, uji reliabilitas dan juga uji hipotesis. Pendekatan yang digunakan structural equation model juga menggunakan PLS atau partial least square di operasikan dengan software computer ialah SmartPLS 3.0.

\section{HASIL \& PEMBAHASAN}

\section{Hasil Penelitian}

Setelah hasil data dari penelitian dikumpulkan selanjutnya di analisis secara deskriptif dan inferensial. Statistik deskriptif untuk mengetahui jawaban responden, dari hasil penyebaran kuesioner kepada seluruh karyawan yang berjumlah 51 akan tetapi hanya terdapat 44 karyawan yang mengisi kuesioner. Dalam penelitian ini terdapat varibel locus of control, kinerja karyawan dan juga kepuasan kerja. Untuk pengukuran dari setiap item pernyataan menggunakan skala likert 1-5 dan di tinjau dengan hasil distribusi frekuensi dan juga rata-rata.

Pada penelitian ini dengan jumlah sampel keseluruhan 44 responden, pria berjumlah 38 karyawan $(86,3 \%)$ dan wanita berjumlah 6 karyawan $(13,7 \%)$. Karyawan yang berusia $\leq 30$ berjumlah 5 karyawan dengan presentase $(11,4 \%)$, lalu karyawan yang berusia 31-41 tahun dengan jumlah 20 karyawan dengan presentase $(45,4 \%)$, lalu karyawan yang berusia $42-51$ tahun berjumlah 14 karyawan dengan presentase $(31,85)$, dan kemudian karyawan yang berusia $>52$ tahun sebanyak 5 karyawan dengan presentase (11,5\%). Seluruh karyawan berjenjang pendidikan SLTA sebanyak 44 karyawan. Selanjutnya, karyawan yang sudah menikah berjumlah 31 dengan presentase $(70,4 \%)$ dan karyawan yang belum menikah berjumlah 13 karyawan dengan presentase $(29,6 \%)$. Untuk selanjutnya, masa kerja karyawan yang $\leq 3$ tahun berjumlah 12 karyawan dengan presentase $(27,3 \%)$, karyawan dengan masa kerja 4-6 tahun berjumlah 24 karyawan dengan presentase $(54,5 \%)$, karyawan dengan masa kerja 7-9 tahun berjumlah 3 karyawan dengan presentase $(6,8 \%)$, dan juga masa kerja $>10$ tahun berjumlah 5 karyawan dengan presentase $(11,4 \%)$.

Dalam penelitian ini menggunakan there box method untuk penilaian mean jawaban dari responden di mana angka yang rendah adalah 1 dan paling tinggi 5. Dan dapat dijelaskan mean penilaian indikator dari locus of control yaitu 4,39 untuk indikator suka bekerja keras, dan 4,32 untuk indikator selalu berusaha, dan 4,30 untuk indikator kepercayaan diri, dan 4,36 untuk indikator keberuntungan, dan juga 4,48 untuk indikator pengaruh orang lain, dengan mean variabel 4,38 yang artinya tergolong kategori tinggi. Untuk mean indikator dari kepuasan kerja yaitu 4,39 untuk indikator kepuasan dalam pembayaran gaji atau upah, dan 4,49 untuk indikator kepuasan terhadap kepuasan itu sendiri, dan 4,44 untuk indikator kepuasan terhadap rekan kerja, dan 4,56 untuk indikator kepuasan terhadap promosi, dan juga 4,51 untuk indikator kepuasan pengawasan kerja, dengan mean variabel 4,47 yang artinya tergolong tinggi. Untuk mean indikator dari kinerja karyawan yaitu 3,68 untuk indikator kemampuan bekerja sama, dan 3,76 untuk indikator kualitas kerja, dan 3,64 untuk indikator kemampuan teknis, dan 3,69 untuk indikator insiatif, dan 3,78 untuk indikator antusianisme, dan 3,80 untuk indikator daya tahan, dan juga 3,58 untuk indikator beban kerja, dengan mean variabel 3,70 yang artinya tergolong dalam kategori tinggi.

Gambar 1 memperlihatkan bahwa outer loadings pada setiap indikator yang memiliki angka lebih dari 0,50. Maka membuktikan bahwa indikator setiap variabel dinyatakan valid. Artinya, penelitian ini menggunakan variabel dengan convergent validity yang baik.

Berdasarkan pada tabel 1,composite reliability pada penelitian ini menggunakan variabel yang lebih dari angkat 0,70 . Dan di tinjau dari data, model variabel telah diuji memiliki reliabilitas yang baik atau telah memenuhi composite reliability. Tabel 1 juga menjelaskan bahwa angka cronbach's alpha 
Prayoga Putra Wardhana. Peran Locus of Control terhadap Kinerja Karyawan melalui Kepuasan Kerja pada Karyawan PT. Ilham Hasil Mandiri Kabupaten Sidoarjo

yang dimiliki seluruh konstruk model melibihi dari 0,70 yang dapat dijelaskan bahwa seluruhnya memiliki reliabilitas yang kuat atau telah mencukupi Cronbach's alpha.

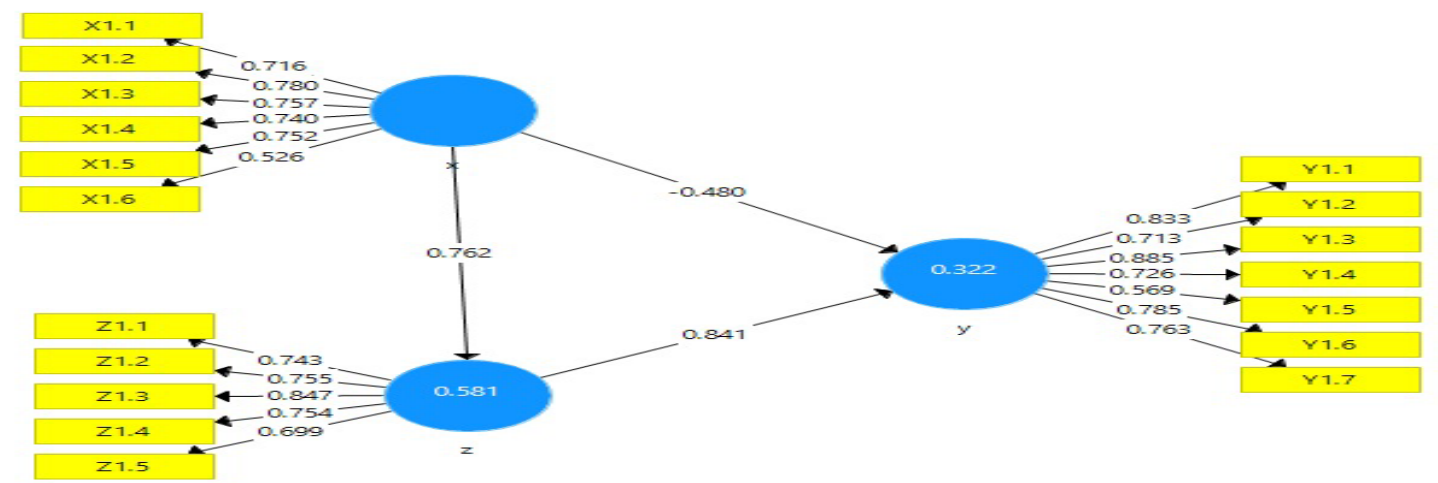

Gambar1. UJI MEASUREMENT MODEL

Tabel 1

COMPOSITE RELIABILITY DAN CRONBACH'S ALPHA

\begin{tabular}{ccc}
\hline Variabel & Composite Reliability & Cronbach's Alpha \\
\hline Locus of Control & 0,862 & 0,808 \\
Kepuasan Kerja & 0,904 & 0,878 \\
Kinerja Karyawan & 0,873 & 0,818 \\
\hline
\end{tabular}

Sumber: Smart PLS 3.0 (data diolah)

Tabel 2

NILAI R-SQUARE

\begin{tabular}{cc}
\hline Variabel & R-Square \\
\hline Locus of Control & \\
Kepuasan kerja & 0,322 \\
Kinerja karyawan & 0,581 \\
\hline Sumber: Smart PLS 3.0 (data diolah)
\end{tabular}

Tabel 2 menunjukkan model dari variabel locus of control dengan kinerja karyawan memberikan 0,581 artinya dapat di interprestasikan, variabel kinerja karyawan bisa di jelaskan dengan variabel locus of control nilai $58,1 \%$.

Tabel 3

PENGARUH LANGSUNG DAN TIDAK LANGSUNG

\begin{tabular}{ccccc}
\hline Hubungan Variabel & Original Sample & T-Statistic & \multicolumn{2}{c}{ Keterangan } \\
\hline $\begin{array}{c}\text { Locus of Control }-> \\
\text { Kepuasan Kerja }\end{array}$ & $-0,480$ & 2,076 & $\geq 1,96$ & $\begin{array}{c}\text { Locus of Control -> } \\
\text { Kepuasan Kerja }\end{array}$ \\
$\begin{array}{c}\text { Locus of Control -> } \\
\text { Kinerja Karyawan }\end{array}$ & 0,762 & 14,299 & $\begin{array}{c}\text { Signifikan } \\
\text { Signifikan }\end{array}$ & $\begin{array}{c}\text { Locus of Control }-> \\
\text { Kinerja Karyawan }\end{array}$ \\
$\begin{array}{c}\text { Kepuasan Kerja -> } \\
\text { Kinerja Karyawan }\end{array}$ & 0,841 & 5,338 & $\geq 1,96$ Signifikan & $\begin{array}{c}\text { Kepuasan Kerja -> } \\
\text { Kinerja Karyawan }\end{array}$ \\
$\begin{array}{c}\text { Locus of control -> } \\
\text { kepuasan kerja -> } \\
\text { kinerja karyawan }\end{array}$ & $-0,403$ & 4,722 & $\geq 1,96$ & $\begin{array}{c}\text { Locus of control -> } \\
\text { kepuasan kerja -> } \\
\text { kinerja karyawan }\end{array}$ \\
\hline
\end{tabular}

Sumber: Smart PLS 3.0 (data diolah) 
Pada tabel 3, dampak dari locus of control pada kinerja karyawan memiliki nilai $t$-statistics 14,299 > 1,96 dengan ini dapat dijelaskan locus of control memberikan pengaruh secara signifikan. Dan angka koefisien estimate 0,762 dan bertanda positif. Artinya semakin baik dari locus of control bertambah baik juga kinerja karyawan.

Selanjutnya, locus of control pada kepuasan kerja memiliki nilai t-statistics 2,076 > 1,96 dengan ini dapat dijelaskan locus of control memberikan pengaruh yang signifikan. Dan angka koefisien estimate $-0,480$ bertanda negatif. Yang bermakna apabila semakin baik locus of control maka kinerja karyawan menurun.

Kemudian kepuasan kerja pada kinerja karyawan memiliki nilai $t$-statistics 5,338 $>$ 1,96 dengan ini dapat dijelaskan kepuasan kerja dapat berpengaruh dengan signifikan. Dan angka koefisien estimate 0,841 yang bertanda positif. Yang bermakna semakin baik tingkat pada kepuasan kerja maka semakin baik tingkat kinerja karyawan.

\section{Pengaruh Locus of Control terhadap Kinerja Karyawan pada PT. Ilham Hasil Mandiri Sidoarjo}

Locus of control berpengaruh signifikan dan positif pada kinerja karyawan, dengan demikian bahwa H1 diterima. Semakin baik locus of control karyawan PT. Ilham Hasil Mandiri Sidoarjo semakin baik kinerja karyawan.

Variabel locus of control suatu pengendalian yang berhubungan dengan variabel kinerja karyawan. Untuk itu, peningkatan kinerja seorang karyawan dipengaruhi dari seberapa baik locus of control karyawan. Jadi jika karyawan mempunyai locus of control yang baik maka karyawan tersebut berkeyakinan bahwa sebuah keberhasilan itu terjadi karena dari diri sendiri, meskipun penuh dengan tekanan karyawan yang mempunyai locus of control yang bagus akan mampu menyikapi dan menghadapi situasi tersebut. Menurut Dudi, et al. (2019), Sari (2018), locus of control berpengaruh positif dan signifikan terhadap kinerja karyawan. Menurut Indriasari \& Angreany (2019), locus of control tidak berpengaruh signifikan dan positif terhadap kinerja kayawan, artinya hipotesis yang diajukan di tolak.

\section{Pengaruh Locus of Control terhadap Kepuasan Kerja Karyawan PT. Ilham Hasil Mandiri Sidoarjo}

Locus of control berpengaruh signifikan dan negatif terhadap kepuasan kerja, dengan demikian bahwa H2 diterima. Tingginya locus of control karyawan PT. Ilham Hasil Mandiri Sidoarjo semakin menurunkan kepuasan kerja.

Locus of control dapat diartikan dengan tingkat keyakinan seseorang atau individu dalam mempresepsikan keberhasilan, dan keberhasilan itu tercapai karena individu tersebut memiliki keyakinan terhadap adanya korelasi antara usaha, keberhasilan dan kepercayaan diri. Dari hasil analisis terdapat makna negatif yang artinya perbandingan terbalik. artinya karyawan mempresepsikan keberhasilan diraih dengan usaha dan kepercayaan diri, akan tetapi tidak adanya dukungan dari beberapa rekan kerja dan juga atasan. Menurut Chhabra \& Mohanty (2016), locus of control berpengaruh positif dan signifikan terhadap kinerja karyawan.

\section{Pengaruh Kepuasan Kerja terhadap Kinerja Karyawan PT. Ilham Hasil Mandiri Sidoarjo}

kepuasan kerja berpengaruh signifikan dan positif terhadap kinerja karyawan. dengan demikian bahwa H3 diterima. Semakin baik tingkat kepuasan kerja pada karyawan PT. Ilham Hasil Mandiri maka semakin baik kinerja karyawan.

Faktor meningkatnya kinerja seorang pegawai dipengaruhi kepuasan kerja, dikarenakan kepuasan kerja adalah suatu keadaan yang di rasakan karyawan dalam bekerja. Menurut Agustyna \& Prasetyo (2020), menyatakan perasaan puas atau tidaknya seorang karyawan mengenai pekerjaanya, jika karyawan merasakan kepuasan kinerjanya menjadi baik dan lebih efektif. Artinya, kepuasan ialah 
Prayoga Putra Wardhana. Peran Locus of Control terhadap Kinerja Karyawan melalui Kepuasan Kerja pada Karyawan PT. Ilham Hasil Mandiri Kabupaten Sidoarjo

sebuah ungkapan perasaan yang dirasakan karyawan mengenai keadaan lingkungan kerjanya bagaimana hubungan antar rekan kerja dan juga situasi kerja.

Menurut Mokoagow et al. (2020) dan Indrawati (2013), kepuasan kerja memberikan pengaruh signifikan dan positif pada variabel kinerja karyawan. Menurut Arda (2017), kepuasan kerja tidak berpengaruh signifikan.

\section{Pengaruh Locus of Control terhadap Kinerja melalui Kepuasan Kerja Karyawan PT. Ilham Hasil Mandiri Sidoarjo}

Kepuasan kerja dapat memediasi secara tidak langsung locus of control pada kinerja karyawan. dengan demikian $\mathrm{H} 4$ diterima. Hal tersebut menunjukkan adanya direct effect locus of control pada kinerja karyawan, juga adanya indirect effect pada kinerja karyawan melalui kepuasan kerja.

Penelitian ini membuktikan adanya mediasi penuh (full mediation). Kepuasan kerja satu-satunya variabel yang dapat memediasi locus of control pada kinerja karyawan. Jadi tingginya locus of control akan meningkatkan kepuasan kerja, jadi karyawan memiliki locus of control yang baik dapat di intreprestasikan bahwasannya karyawan tersebut termasuk memiliki kepuasan kerja yang baik yang sehingga kinerja dari karyawan tersebut meningkat.

Menurut Wahyuni et al. (2016), kepuasan kerja memediasi locus of control terhadap kinerja karyawan. Menurut Narendra (2018), locus of control berpengaruh positif secara tidak langsung dan juga tidak signifikan pada kinerja karyawan melalui kepuasan kerja yang diartikan locus of control tidak memiliki keterkaitan secara tidak langsung pada kinerja melalui kepuasan kerja.

\section{KESIMPULAN}

Hasil dari analisis dan penjabaran di atas bahwa: locus of control berpengaruh positif dan signifikan terhadap kinerja karyawan. locus of control berpengaruh negatif dan signifikan terhadap kepuasan kerja. kepuasan kerja berpengaruh positif dan signifikan pada kinerja karyawan. locus of control berpengaruh negatif dan signifikan terhadap kinerja karyawan melalui kepuasan kerja.

Setelah dilakukannya penelitian adapun saran praktis yang ditarik dari observasi, pengamatan, wawancara serta dilakukannya analisis. Adapun saran yang dikemukakan adalah perlunya interakasi dan komunikasi lebih mendalam terhadap karyawan agar mengetahui permasalahan yang dirasakan oleh karyawan dan di berikannya solusi yang terbaik dan juga perusahaan perlu adanya melakukan pengelolaan personalia yang baik, dengan cara memberikan reward dengan bentuk gaji atapun upah tambahan terhadap karyawan yang kinerjanya baik, sehingga seluruh karyawan akan berlomba untuk meningkatkan kinerjanya. saran ini agar perusahaan dapat mengoptimalkan kinerja sumber daya manusia yang dimiliki oleh PT. Ilham Hasil Mandiri Sidoarjo dalam proses bekerja, dan diberikannya rangsangan terhadap karyawan agar seluruh karyawan semangat dan bertanggung jawab dalam bekerja. Adapun masukan terhadap peneliti selanjutnya dengan menggunakan variabel work life balance dikarenakan adanya karyawan yang tidak mampu mengatur dan membagi tanggung jawab pekerjaan dengan kehidupan keluarga, yang sehingga terjadi konflik antara karir pekerjaan dengan kehidupan keluarga.

\section{DAFTAR PUSTAKA}

Agustyna, A., \& Prasetyo, P. P. (2020). Pengaruh Persepsi Dukungan Organisasi Dan Kepuasan Kerja Terhadap Kinerja Karyawan Pada PT. Great Citra Lestari. Jurnal Mitra Manajemen, 2(4), $273-$ 285. http://e-jurnalmitramanajemen.com/index.php/jmm/article/view/125/69.

Ali, S., \& Farooqi, Y. A. (2014). Effect of Work Overload on Job Satisfaction, Effect of Job Satisfaction on Employee Performance and Employee Engagement (A Case of Public Sector University of Gujranwala Division). International Journal of Multidisciplinary Sciences and Engineering, 5(8), 23-30. 
Arda, M. (2017). Pengaruh Kepuasan Kerja Dan Disiplin Kerja Terhadap Kinerja Karyawan Pada Bank Rakyat Indonesia Cabang Putri Hijau Medan. Jurnal Ilmiah Manajemen dan Bisnis, 18(1), 45-60. https://doi.org/10.30596/jimb.v18i1.1097

Candra, Y. (2019). Pengaruh Self-Efficacy, Locus of Control Terhadap Kepuasan Kerja Karyawan Dengan Budaya Organisasi Sebagai Variabel Pemoderasi Puskemas Air Haji Kabupaten Pesisir Selatan. Jurnal Ekonomi dan Manajemen Sistem Informasi, 1(September), 7-16. https://doi.org/10.31933/JEMSI

Chandraningtyas, I., Musadieq, M., A., \& Utami, H., N. (2015). Pengaruh Kepuasan Kerja dan Motivasi Kerja Terhadap Kinerja Karyawan Melalui Komitmen Organisasional (Studi pada karyawan PT Kusuma Karya Persada yang outsorcing di PT Sasa Inti Probolinggo). Jurnal Profit, 6(2), 32-43.

Changgriawan, G., S. (2017). Pengaruh Kepuasan Kerja dan Motivasi Kerja terhadap Kinerja Karyawan One Way Production. Agora, 5(3), 123-131.

Chhabra, B., \& Mohanty, R., P. (2016). Moderating role of locus of control in the relationship between job satisfaction and organisational citizenship behaviour: a study of the Indian IT sector. International Journal of Indian Culture and Business Management, 13(3), 288. https://doi.org/10.1504/ijicbm.2016.078834

Dudi, A., Moeins, A., \& Elfiswandi. (2019). Pengaruh Komitmen, Kompetensi, dan Locus of Control Terhadap Kinerja Pegawai Pemerintahan. Jurnal Informatika Ekonomi Bisnis, 1(4), 1-7. https://doi.org/10.37034/infeb.v1i4.8

Hidayat, C. (2012) Pengembangan Produksi Ayam Lokal Berbasis Bahan Pakan Lokal. Wartazoa, 22(2), 85-98.

Hidayat, M., \& Dewi, A., S. (2016). Pengaruh Budaya Organisasi Dan Locus of Control Terhadap Kinerja Pegawai Cabang PT. Pegadaian (Persero) Tarandam padang, Jurnal Ilmu dan Riset Manajemen, $1-10$.

Indrawati, A., D. (2013). Pengaruh Kepuasan Kerja Terhadap Kinerja Karyawan Dan Kepuasan Pelanggan Pada Rumah Sakit Swasta Di Kota Denpasar. Jurnal Manajemen, Strategi Bisnis Dan Kewirausahaan, 7(2), 135-142.

Indriasari, D., P., \& Angreany. (2019). Pengaruh Locus of Control Dan Beban Kerja Badan Pendapatan Daerah Provinsi Sulawesi Selatan. YUME: Journal of Management, 2(3), 1-19.

Isnanto, T., Indrawati, M., \& Muninghar. (2020). Analisis Pengaruh Budaya Organisasi, Locus of Control, Stress Kerja terhadap Kinerja Pegawai dan Kepuasan Kerja sebagai Variabel Intervening. Jurnal Mitra Manajemen, 4(5), 789-803.

Lisnawati., Samsudin, A., \& Jhoansyah. (2019). Peran Locus of Control Dan Stres Kerja Terhadap Kepuasan Kerja Karyawan. Journal of Management and Bussines (JOMB), 1, 394-403.

Maulidya, A., Gunawan, J., \& Ardiantono, D., S. (2019) Perancangan dan Pengelolaan Rantai pasok Produksi Pakan Ternak Unggas di PT. Charoen Phokphand Indonesia (Tbk) Sidparjo Jawa Timur. Jurnal Sains Dan Seni ITS, Volume 8, Nomor 2, 2337-3520.

Mokoagow, Z., M., Soegoto, A., S., \& Sumarauw, J., S., B. (2020). Effect of Work Satisfaction and Career Develoment to Employee Performance in PT. PLN (PERSERO) Suluttenggo REGION. Jurnal EMBA, 8(1), 491-500. 
Prayoga Putra Wardhana. Peran Locus of Control terhadap Kinerja Karyawan melalui Kepuasan Kerja pada Karyawan PT. Ilham Hasil Mandiri Kabupaten Sidoarjo

Mootalu, J., Adolfina, \& Uhing, Y. (2019) The Influences of Locus of Control and Transformational Leadership. Jurnal EMBA, 7(1), 381-390.

Mulyadi., Syahrizal., \& Patrisia, D. (2018). Effect of Locus of Control, and Self-Efficacy on Organizational Citizenship Behavior with Job Satisfaction as Intervening Variables in Padang Panjang City Government. Advances in Economics, Business and Management Research, Volume 64, 901-909. https://doi.org/10.2991/piceeba2-18.2019.81

Mulyani, S., R., Sari M., W., Sari V., N., \& Tawakalni, W. (2019). The Effect Locus of Control and Organizational Culture Toward Employee Performance with Organizational Commitments as Intervening Variable. JEMA: Jurnal Ilmiah Bidang Akuntansi Dan Manajemen, 16(2), 147. https://doi.org/10.31106/jema.v16i2.2631

Narendra, N., M. (2018). Pengaruh Locus of Control Dan Komitmen Organisasi Terhadap Kinerja Karyawan Melalui Kepuasan Kerja Di RSU Al-Islam H. M. Mawardi Sidoarjo. Jurnal Ekonomi dan Manajemen, 19(2), 621-636.

Sari, D., P. (2018). Pengaruh Locus of Control, Motivasi Dan Kepuasan Kerja Terhadap Kinerja Karyawan Bank Nagari Cabang Simpang Empat Pasaman Barat. EKOBISTEK Fakultas Ekonomi, 7(1), 9-18.

Subhan, M., Saleh, H., \& Sapiri, M. (2019). Pengaruh Locus of Control Terhadap Kinerja Pegawai Pada Dinas Pendapatan Daerah Kota Makasar. Jurnal Ecosystem, Volume 18, Nomor 3, 18, $1242-1250$.

Sugiyono. (2010). Penelitian Kuantitatif dan Kualitatif $R \&$ D (11th ed.). Bandung: Alfabeta.

Wahyuni, E., S, \& Rosmida. (2017). Analisis Pengaruh Budaya Organisasi, Locus of Control Terhadap Kinerja Aparat Pemerintah Daerah Dan Kepuasan Kerja Sebagai Variabel Intervening. Jurnal Inovasi Dan Bisnis, 5(1), 13-28.

Wahyuni, E., S., Taufik, T., \& Ratnawati, V. (2016). Pengaruh Budaya Organisasi, Locus of Control, Stres Kerja Terhap Kinerja Aparat Pemerintah Daerah Dan Kepuasan Kerja Sebagai Variabel Intervening. Jurnal Manajemen, 5(1), 189-206.

Yusnaena, \& Hayati, S. (2018). Pengaruh Locus of Control terhadap Kinerja Karyawan Bank Syariah Mandiri KC Padang. Menara Ekonomi, IV (3), 2579-5295. 